\title{
Growth and vegetative reproduction of Chilean flame creeper (Tropaeolum speciosum) in two diverse climates of New Zealand
}

\author{
C.A. Dowsett and T.K. James \\ AgResearch, Ruakura Research Centre, Hamilton 3240, New Zealand \\ Corresponding author: claire.dowsett@agresearch.co.nz
}

Chilean flame creeper is a summer active perennial vine growing to $5 \mathrm{~m}$ or more. It has an extensive rhizomatous root system and has proved very difficult to control with herbicides. Both the above and below ground stems are soft, without any tough outer skin or bark. For these studies plants were grown in 50 litre tubs in Waikato and Southland and four replicate tubs were destructively harvested at monthly intervals to measure the root structure and top growth. Plant material for both studies was sourced from an infestation at Mangaweka. The rhizomes appeared to be entirely replaced with none of the remaining original root fragments sprouting in the second year. Also, the growing rhizomes initiated secondary rhizomes before they emerged. It appears that this is the reason this species is difficult to control as the herbicides were not translocating into the secondary rhizomes. The growth of Chilean flame creeper from Waikato and Southland was markedly different. After 4 months growth the Waikato plants averaged $151 \mathrm{~mm}$ of primary rhizome and nine emerged shoots while Southland plants averaged $116 \mathrm{~mm}$ of rhizome and three emerged shoots. At this time, however, plants grown in both locations had tertiary rhizomes.

\section{Yellow bristle grass seed killed in maize silage}

\author{
M.R. Trolove and C.A. Dowsett \\ AgResearch, Ruakura Research Centre, Hamilton 3240, New Zealand \\ Corresponding author: michael.trolove@agresearch.co.nz
}

Yellow bristle grass (Setaria pumila) is a serious weed that reduces dairy farm profitability and could potentially infest productive land throughout New Zealand. Supplementary feed is used extensively in the dairy industry and farmers are concerned that yellow bristle grass seed may be spread with maize silage. Previous studies showed that its seeds did not survive burial in covered silage stacks after 1 week. To further investigate the decline in seed viability, mesh bags containing 50 seeds were buried at 0 and/or $400 \mathrm{~mm}$ depth in two covered Waikato silage stacks and retrieved after 1, 2, 3, 5 and 7 days. Germination prior to seed burial was $69 \%$ and viability using tetrazolium staining was $88 \%$. Germination was reduced after 1 day to $12-36 \%, 2$ days to $0-30 \%, 3$ days to $0-4 \%$ and 5 days to $0 \%$. Viability was reduced after 1 day to $62 \%, 2$ days to $16 \%$ and 3 days to $0 \%$. Temperatures peaked at $36^{\circ} \mathrm{C}$ and $\mathrm{pH}$ was reduced over 1 week from 5.0 to 4.0. Temperature and $\mathrm{pH}$ conditions during this study were not considered sufficient for rapid seed decay and therefore it appeared that chemicals released after ensiling were responsible. Further investigation into mechanisms behind this rapid decay and its potential for effective weed seed control is warranted. 